\title{
COVID-19 and Methylene Blue
}

Dear Editor, I would like to comment on the article "COVID-19 should be a methylene blue "promoter"[1]". Evora noted that "I decided to resubmit the letter now, considering that COVID-19 should be a methylene blue 'promoter,' and the dye can get the lifesaving status it deserves ${ }^{[1]}$." In fact, the use of classic available agent as a possible therapeutic agent for the emerging COVID-19 should be supported. It is better than do nothing. Many classic drugs such as hydroxychloroquine are proposed and tested for managing COVID-19 ${ }^{[2]}$. At the moment, we have to take the risk of a new alternative proposal for the treatment of COVID-19 such as convalescent plasma therapy ${ }^{[3]}$. Using a safe and well-known agent might not have a confirmation for its efficacy but we have many data on its safety, and it might be a good alternative option compared to a totally unknown new alternative.

\section{Viroj Wiwanitkit ${ }^{1}, \mathrm{MD}$}

(iD) https://orcid.org/0000-0003-1039-3728

${ }^{1}$ Padmashree Dr. DY Patil University, Dr. DY Patil University, Navi Mumbai, India

E-mail:wviroj@yahoo.com

\section{REFERENCES}

1. Evora PRB. COVID-19 should be a methylene blue "promoter". Braz J Cardiovasc Surg. 2020;35(4):604-5. doi:10.21470/1678-9741-1-2020-0607.

2. Joob B, Wiwanitkit V. Evidence of protective effect of hydroxychloroquine on COVID-19. J Rheumatol. 2020;47(10):1587. doi:10.3899/jrheum.200638.

3. Wiwanitkit V. Convalescent plasma therapy in the treatment of COVID-19: some considerations: correspondence. Int J Surg. 2020;80:26. doi:10.1016/j.jjsu.2020.06.029. 